\title{
SVBR-100 Nuclear Technology as a Possible Option for Developing Countries
}

\author{
Vladimir Petrochenko', Georgy Toshinsky1,2*, Oleg Komlev1 \\ ${ }^{1}$ JSC “AKME-Engineering”, Moscow, Russia \\ ${ }^{2}$ FSUE SSC RF-IPPE, Obninsk, Russia \\ Email: ${ }^{*}$ toshinsky@ippe.ru
}

Received 20 January 2015; accepted 28 July 2015; published 31 July 2015

Copyright (C) 2015 by authors and Scientific Research Publishing Inc.

This work is licensed under the Creative Commons Attribution International License (CC BY). http://creativecommons.org/licenses/by/4.0/

(c) ()

\begin{abstract}
Many developing countries need ecologically clean power sources (PS). The nuclear power plants are such sources. However, a great number of the developing countries do not possess developed large capacity power systems. Moreover, currently in the developing countries, there are no highly skilled personnel to provide construction and reliable and safe operation of the nuclear plants, which are complex and potentially hazardous systems. In some countries, the level of terroristic threat is extremely high. For that reason, there are specific requirements to the nuclear PSs intended for use in the developing countries. In the presented report, the specific requirements which must be met by the NPT proposed for use in developing countries are formulated, basic statements of the SVBR-100 concept are presented, design and principal scheme of the reactor facility are described, major characteristics of SVBR-100 are summarized.
\end{abstract}

\section{Keywords}

SVBR-100, Reactor, Nuclear Power Technology, Nuclear Power Plant, Inherent Self-Protection, Passive Safety

\section{Introduction}

Now the population in the world is growing mainly due to developing countries where electricity is in deficit. The most expedient way to reduce the deficit in electricity is implementation of nuclear PSs which can provide power safety of the country, reduce dependence on external suppliers of power and power resources, political and cost conjuncture at the market of fuel resources and transport services, assure socially acceptable tariffs on power production for the population and industry, and as a result to heighten a living standard of the population.

*Corresponding author. 
Use of the NPT will also enable to prevent burning of large amounts of fossil fuel that will considerably reduce exhaust of harmful substances in the environment and result in ecological enhancement.

Along with these, when choosing the NPT, some specific features in developing countries should be taken into account. In particular, the most important features are as follows:

- Lack of the skilled personnel for reliable and safe operation of the reactor facility (RF), lack of the backgrounds for personnel's training.

- Lack of builders and assembly workers for providing high quality of assembly works at the NPP site.

- Lack of large electrical grid systems for transmitting electricity to long distances.

- A wide variety of demands both in PS power and purpose (generation of electricity, generation of heat water for the population and industrial enterprises, sea water desalination).

- Lack of adequate political stability in some developing countries.

- A high level of terroristic threat in some developing countries.

- A high risk of unauthorized proliferation of nuclear fissile materials (NFM).

- Lack of infrastructure required for NPT functioning.

- Limited investment opportunities.

Moreover, when choosing the NPT, one should take into account the general conditions typical for both developed and developing countries. Those conditions are uppermost the following:

- The population's radiophobia that increased much after the disaster happened at nuclear power plant (NPP) Fukushima 1.

- Making use of an anti-nuclear state of public opinion for achieving the political goals.

- In both developed and developing countries the available resources of natural uranium for large-scale development of nuclear power (NP) are economically limited.

- The necessity to assure competitiveness of nuclear PSs with alternative PSs at the sites of their location.

- Postponed problems of handling the spent nuclear fuel (SNF) and long-lived radioactive waste (RAW).

Below the requirements to the NPTs purposed for use in developing countries are formulated, the basic conceptual statements of the innovative NPT based on SVBR-100 reactors for meeting the proposed requirements are summarized and the description of specific features of the NPT based on RF SVBR 100 is presented.

In the presented manuscript the specific requirements, which must be met by the NPT proposed for use in developing countries, are reviewed. The basic statements of the SVBR-100 concept are presented. The design and principal scheme of the reactor facility are described and major characteristics of SVBR-100 are summarized.

\section{Requirements to the NPT in Developing Countries}

NP development in developing countries puts forward a number of requirements to the type of the NPT proposed for use, which have been followed from the provisions listed above.

1) There must be assured elimination of the necessity of population evacuation and protection measures beyond the NPP site in events of any failures of the equipment, personnel's errors and their combinations as well as in events of ill-intentioned actions. This is especially viable when the PS is used in a mode of co-generation with production of thermal power, when it is necessary to install nuclear heat power plants (NHPP) not far from the population centers.

2) With due account of the large potential market for small and medium-sized power units in developing countries the RF must be export-available not only from the standpoint of assuring safety (including that in conditions of terroristic attacks), but from the standpoint of NFM non-proliferation.

3) Commercial scales of NP development in developing countries means changeover of nuclear power-units to the category of widespread industrial objects from unique ones. From that standpoint operating the RF must be most simplified concerning the requirements to the personnel's qualification that must be also provided by high level of RF inherent self-protection and passive safety that makes possible simplification of the scheme and design of the nuclear steam supplying system (NSSS) due to elimination of lots of safety systems required for traditional type RFs.

4) Because in developing countries the demands in PS power differ much (100 - $600 \mathrm{MWe})$, the modular structure of the NSSS is more preferable as it can provide any power divisible by the power of a single module and therefore eliminate many-type designs of RFs.

5) Due to a great number of the required power-units, it is necessary to organize quantity production of the RFs, 
and their fabrication must eliminate use of the unique equipment to the most possible extent. That is, it must be available at lots of engineering factories and does not hinder development of large-scale nuclear power based on light water reactors (LWR), for which the high-pressure vessels are required.

6) In the future wide-scale implementation of nuclear PSs will require large quantities of nuclear fuel. In conditions of limited resources of natural uranium that calls forth the necessity for development of that power on the basis of fast reactors which can operate in the closed nuclear fuel cycle (NFC) in a mode of fuel self-providing without consumption of natural uranium.

7) The indispensable condition of nuclear PS implementation is their competitiveness with thermal power plants (TPP) on fossil fuel. To meet that requirement it would be important to reduce maximally the schedule terms of plant construction that can be provided firstly by increasing the scopes of factory production of the RFs and transportation of the ready units to the construction site by railway or other kinds of transport with a minimal scopes of works on the site, as well as serial (conveyer) production.

8) Commercialization of the NPT in developing countries must be preceded by construction and operation of the entirely referent experimental-industrial power-unit for the purpose to verify safety, technical and economical characteristics and operating abilities of the RF. That will make possible minimization of the technical and investment risks, provide the conditions for attraction of private investments and realize the concept "built, own, operate (or lease)" at the point that all residual risks are taken by the Supplier that will assure the most attractable conditions for developing countries.

\section{Specific Features of the NPT Based on RFSVBR-100}

\subsection{High Level of Inherent Self-Protection and Passive Safety}

During a historically short period of NP development, use of nuclear power was followed by a number of low probability accidents of various extent of severity, which caused strong exhausts of radioactivity into the environment and/or considerable economical losses:

- Three Mile Island Unit 2 (TMI-2) accident in 1979 (USA). The accident in PWR type reactor resulted in core meltdown due to loss of primary circuit coolant caused by technical failure (the safety valve remained open) and inadequate personnel's actions. Today, the power-unit cannot be restored, radioactivity release has been localized within the containment.

- Chernobyl disaster occurred on 26 April 1986. An explosion of steam in reactor RBMK at Unit 4 resulted in catastrophic exhaust of large quantities of radioactivity into the atmosphere. The explosion was caused by prompt neutrons runaway because of violation of the operating regulations and defects in the reactor design.

- In 1995 fire occurred at fast sodium reactor "Monju” (Japan). It happened as a result of non-radioactive sodium leak in the intermediate circuit pipeline and inadequate personnel's actions. It had taken 15 years to perform repair-and-renewal works.

- In 2011 the disaster happened at NPP Fukushima 1 (Japan) because of the earthquake and following tsunami. Long blackout of BWR type reactors led to termination of removal of heat decay from the reactor cores and pools-storages of SNF. It was followed by meltdown of fuel and exhaust of radioactivity caused by steam discharge from the primary circuit and explosions of hydrogen-air mixture generated due to intensive steamzirconium reaction.

The initial events for these accidents are very unlike. These are such as personnel's errors, technical failures, defects in the reactor designs and extremal external impacts. However, there is one common cause of the severe consequences of all these accidents which are the result of releasing the various types of potential energy accumulated in different materials, first of all, in the RF coolant:

- Compression energy of water coolant.

- Chemical energy of interaction of water steam with zirconium.

- Chemical energy of interaction of hydrogen produced by steam-zirconium reaction with air oxygen.

- Energy of chemical interaction of sodium with air oxygen.

Due to these accidents, in some countries the population's trust in the NP safety was decreased and in order to enhance the confidence to the NP the necessity to make corrections in the strategy of long-term development of NP arose.

First, the necessity for development of the reactors with safety level eliminating the severe accidents, which require to take protection measures or even population evacuation, was highlighted in paper [1] in 1985 before 
the Chernobyl disaster occurred. In that paper those class reactors were named "inherently safe reactors". The general principles for construction of those reactors were justified in paper [2] in 1990 after the Chernobyl accident happened.

In this paper it is highlighted that for the population the possibility of the catastrophic consequences of the nuclear accident is much more important than the low probability of its realization. From the standpoint of the nuclear community and educated part of the population that perception of the NP is not reasonable. It may seem strange as in accordance with the reliably stated statistical data, the risks caused by operation of industrial enterprises and their fuel-power infrastructure are many orders greater than the corresponding risks for NP while the existing NPTs are used [3].

Nevertheless, that population acceptability of the NP should be taken into consideration as an objective factor and the high safety level of the NPP should be validated by "transparent" arguments without use of probabilistic analysis methods that is possible in case of eliminating the very reasons of those accidents.

In the system approach, safety and hazard are considered as interconnected concepts. Therefore, in order to understand better how to achieve a high safety level of the nuclear power facility, the nature of hazard peculiar to nuclear power systems should be analyzed.

The hazard from the RF is determined by three factors:

1) Radiation potential accumulated, i.e., total radioactivity (more exactly, radiotoxicity) contained in the reactor facility.

2) Residual heat release of radioactive fission products decay.

3) Amount of radiotoxicity-released products into the environment for different initial events.

The first and second factors do not depend strongly on the RF type, because total radioactivity contained in the RF and determined mainly by the amount of fission products is associated primarily with thermal power of the reactor and duration of its operation at this power level, i.e., by energy production. These factors are peculiar to each NPT and cannot be reduced.

The third factor depends strongly on the RF type and is determined by reactivity margin, reactivity feedbacks, design features, and potential energy accumulated in the RF materials (nuclear energy, internal thermal energy, coolant compression energy, chemical energy), which in an event of its release can cause exhaust of radiotoxicity into the environment. Therefore, the hazard associated with the RF (for identical power levels and operation time) will be determined by the third factor that can be reduced at the design stage of the project.

The nuclear fission energy, which can be released under conditions of reactivity accidents, can and must be minimized as early as at the reactor design stage by limiting the reactivity margin, use of negative reactivity feedbacks, and by various engineering solutions in the control and protection system (CPS), which exclude a possibility of prompt neutrons runaway of the reactor ${ }^{1}$.

At the same time the potential (non-nuclear) energy stored in coolant used in the RF primary circuit coolant is an inherent property of coolant material and cannot be changed by engineering solutions.

Upgrade of safety of the NPPs based on traditional type RFs (with high amount of potential energy stored in coolant) requires increase of the number of safety systems and defense-in-depth barriers, which decrease the probability of arising the severe accidents (but do not eliminate deterministically the reasons for their happening) and weight of their consequences. While assessing that probability, the failures of the basic equipment, safety systems, protection barriers, and personnel's errors are considered as random events.

However, because of high diversity and complication of developing processes and lack of the certain initial data required for calculation, there are many uncertainties in the results of safety substantiation by probabilistic safety analysis (PSA) methods as applicable to severe accidents, their probability being very low $\left(\sim 10^{-6}\right.$ per reactor-year and less). Therefore, these results do not possess the credibility value as necessary.

Moreover, use of probabilistic analysis methods makes no sense if we consider such initial events, (for example, over-normal external environmental effects or man-caused impacts, ill-intended actions) when all active

\footnotetext{
${ }^{1}$ At this point it should be highlighted that runaway of reactor RBMK at the Chernobyl NPP happened because these requirements were not met at the stage of the reactor design: the reactor possessed high positive steam reactivity effect, and when the deviation from the operating regulations took place, the positive reactivity was inserted by the emergency protection rods at the initial section of their falling into the core At the same time prompt neutron runaway of the reactor, which coolant does not accumulate the stored potential energy that can cause damage of protection barriers, can result in core damage but not in radioactivity exhaust into the environment. However, taking into account the maximal rate of insertion of positive reactivity that has been designed in the absorbing rods drivers and compensating action of the negative feedbacks, that runaway of the reactor should be considered as a postulated one in an event of failure of actuation of all emergency protection systems.
} 
safety systems (or non-active safety systems with movable parts), which are in a standby mode, and the protection barriers can be disabled, and radioactivity release can achieve a disastrous level. A well-known fact is explosions performed by terrorists at NPP "Lemoniz" (Spain) in 1978 and 1979 [4]. The importance to consider such scenarios is verified by the fact that they have also been addressed by the IAEA [5].

Along with that, the PSA methods are useful and necessary to assess the frequency of the accidental events including such severe ones as core damage in case it is not followed by release of potential energy that can cause destruction of protection barriers and consequent exhaust of radioactivity. Such approach to the requirements to safety of Generation IV reactors (the concept of about zero-point radiology risk for the population in an event of any external initiating impacts coupled with a probabilistic approach to the frequency of core damaging by internal initiating impacts) is considered in [6].

For the risk of radioactivity release from different type RFs being at a similar, socially acceptable level, the number of safety systems and defense-in-depth barriers, which strongly determine the NPP technical and economical characteristics, can be reduced in case of decreasing the potential energy accumulated in the RF, mainly in coolant. At this point, it is important that the high safety level at a low value of potential energy stored in coolant can be achieved virtually "free of charge", mainly, due to elimination of the very causes of severe accidents, i.e., deterministically.

The effect of potential energy stored in coolant on safety and economic parameters is considered in paper [7]. Water coolant accumulates all kinds of stored potential energy which can cause damage of the RF; coolant compression energy, energy released in events of steam-zirconium reaction and explosion of hydrogen and air mixture $21 \mathrm{MJ} / \mathrm{m}^{3}$. There is no pressure in case of sodium coolant, but there is chemical energy $9.4 \mathrm{MJ} / \mathrm{m}^{3}$. Under certain conditions its release can cause fire and explosion.

These factors of hazard can be compensated by the certain economic losses. So, there is a conflict between economic and safety requirements. The highlighted conflict is eliminated in case of using heavy liquid metal coolants (HLMC) such as eutectic lead-bismuth alloy and pure lead, as well as molten salts. In those reactors there is no stored potential energy of coolant compression and chemical energy, which under certain conditions can cause damage of fuel and primary circuit, loss of coolant and destruction of protection barriers.

Therefore, the SVBR-100 type reactors assure deterministical elimination of the severest accidents which cause radioactivity exhaust and require population evacuation. That makes possible with a minimal risk use such reactors in developing countries.

The main effect in providing a high safety level of the SVBR-100 RF is achieved due to use of the fast neutron reactor, HLMC and integral design of the reactor with entire elimination of pipelines and valves with radioactive coolant beyond the reactor monoblock (RMB) vessel (see Figure 1). This has been verified by performed computations and development works [8].

The reactor possesses a negative void reactivity effect and negative feedbacks, the efficiency of the strongest absorbing rod does not exceed $1 \$$ - the efficient delayed neutrons fraction. And those coupled with technical realization of the CPS eliminate prompt neutron runaway of the reactor.

The high boiling point of coolant heightens reliability of heat removal from the core, and safety due to lack of the heat transfer crisis. Also, being coupled with a provided safeguard casing of the monoblock vessel, that eliminates loss of coolant accidents (LOCA) and high pressure radioactive exhausts.

The low pressure in the primary circuit reduces the risk of tightness failure. It makes possible to decrease the thickness of reactor vessel walls and diminishing the limitations imposed on the rate of temperature change according to the thermal-cycling strength conditions.

The RF components do not contain materials releasing hydrogen as a result of thermal and radiation effects and chemical reactions with coolant, water and air. Therefore, in an event of tightness failure in the primary circuit the likelihood of chemical explosions and fires is virtually eliminated.

The RF inherent self protection and passive safety properties make it possible to couple realization of much of safety functions and normal operating functions. At this point, the safety systems do not contain elements, in which actuation can be blocked in an event of failure or impact of any human factors:

- Removal of residual heat decay is provided passively by natural circulation of LBC in the primary circuit. This is realized by transferring heat via four independent channels into the SG to the secondary circuit water and then to water of the passive heat removal system (PHRS) tank, with removal of produced steam to the atmosphere. For that purpose condenser is mounted in the PHRS tank under the water level. In the process of heat decay removal the steam from the separator is transferred to the condenser and condensate is discharged 
into the separator via the steam pressure control valve. The valve is closed when the steam pressure is reduced in order to eliminate overcooling of the condensate (see Figure 2). This represents a grace period of about three days long without exceeding the allowed temperature limits.

- In an event of large leak in several SG tubes, localization of SG leak and RMB protection are also provided passively when the steam pressure in the gas system is increased over $0.5 \mathrm{MPa}$. This is provided by actuation of the bursting membranes and discharge of steam into the bubbling device. (Operating experience has revealed that in an event of small leak in the SG, the RF does not need to be shut down at once).

- When LBC temperature is increased over a dangerous value, the rods of the additional emergency protection system, which are mounted in "dry" channels and do not have drivers on the reactor lid, actuate passively by gravity due to fusible locks, which are made of the alloy with a corresponding melting temperature and hold the rods in the upper position at normal temperature modes.

Moreover, in an event of postulated failure of all four channels of the PHRS, it is provided to flood the reactor well with water from the bubbling devices mounted above and transfer heat via the mono block vessel, air gap and protective casing to the water with further removing the produced steam to the atmosphere.

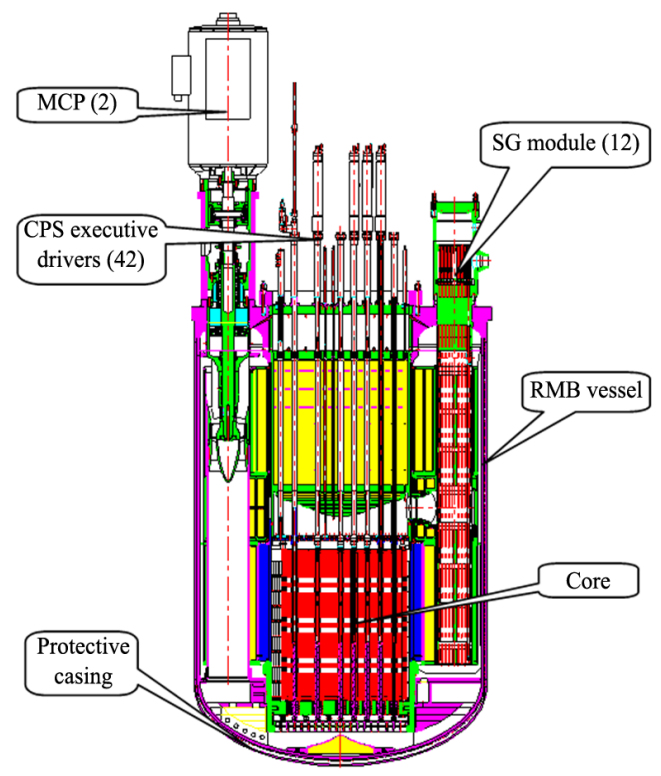

Figure 1. Reactor monoblock.

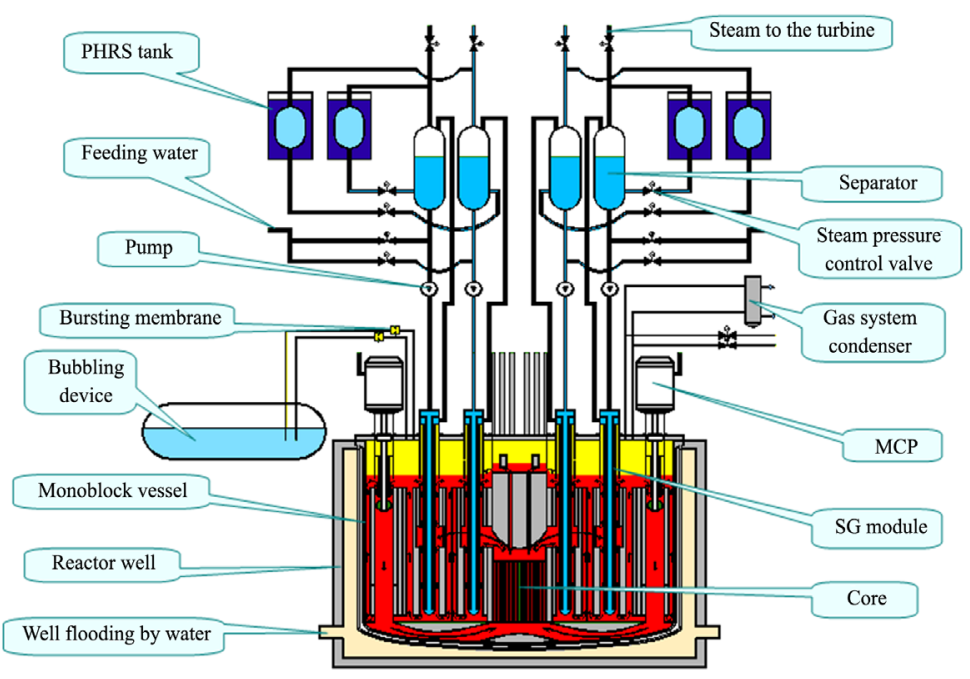

Figure 2. Hydraulic diagram of RF SVBR-100. 
To reveal safety potential of the SVBR-100 RF, there were performed computations of radiational consequences caused by damage of the power-unit containment, damage of the reinforced-concrete overlapping over the reactor, tightness failure in the primary circuit gas system with direct contact between the coolant surface and atmospheric air, damage of all four channels of the SG PHRS and simultaneous total "blackout" of the NPP [9]. The superposition of such initial events is much beyond the normative safety regulatory documentation requirements including IAEA requirements [10] and can occur under the following circumstances: military actions, NPP capture by terrorists, extreme nature and man-caused actions. Therefore, today it is not considered while making justification of NPP safety.

The results of considerations and computations have revealed [9] that the integrity of the reactor monoblock vessel installed in the reinforced-concrete well below the ground level is maintained, the core will not be damaged in case makeup of the reactor well with water will be organized not later than twenty four hours after all channels of the SG PHRS have been damaged (transfer of necessary makeup water is provided by five ten-ton fire-engines per a day), and reactivity exhaust into the environment has not achieved the values requiring population evacuation.

These enable speaking not only about RF SVBR-100 tolerance to the equipment failures and personnel's errors and their multiple super-positions but also about tolerance to malevolent actions when all special systems can be intentionally disabled.

\subsection{Brief Description of RF SVBR-100}

These enable speaking not only about RF SVBR-100 tolerance to the equipment failures and personnel's errors and their multiple super-positions but also about tolerance to malevolent actions when all special systems can be intentionally disabled.

The considered NPT [11] is grounded on critical review of unique experience of development and operation of LBC cooled reactors at Russian NSs (15 reactors, 80 reactor-years) [12] and experience of operating the fast reactors with sodium coolant.

Characteristics of the SVBR-100 RF are as follows:

1) A fast neutron reactor with chemically inert LBC, i.e. eutectic lead-bismuth alloy in the primary circuit. Boiling point of $\mathrm{LBC}$ is $1670^{\circ} \mathrm{C}$, melting point of $\mathrm{LBC}$ is $124.5^{\circ} \mathrm{C}$.

2) An integral design of the reactor, when the whole primary circuit equipment is mounted in a single strong RMB vessel. Valves and LBC pipelines are completely eliminated (see Figure 1).

3) The reactor monoblock with a safeguard casing is installed in the reinforced-concrete well.

4) The basic components of the reactor monoblock and reactor facility are designed as separate modules. At this point, an opportunity of their replacement and repair is ensured.

5) On ending the core lifetime, fuel unloading will be performed at once, cassette-by-cassette, and fresh fuel will be loaded as a single cartridge (new core). After the fuel sub-assemblies (FSA) have been unloaded from the reactor, they are put in steel capsules with liquid lead and then to the storage with natural circulation of atmospheric air.

6) Repair of the primary circuit equipment and refueling are performed without LBC draining under maintaining it in liquid state due to residual heat release from the core or operation of the heating system. At this point, experience of operating the NS RF has been accounted: when those works were performed, air penetrated into the primary circuit that caused accumulation of slags and blocked the coolant flow rate.

7) A two-circuit scheme of heat removal and a steam generator (SG) with multiple compulsory circulation (MCC) over the secondary circuit are used (see Figure 2).

8) Natural circulation (NC) of coolants in heat-removal circuits of the reactor monoblock is sufficient to ensure passive removal of heat from the reactor without dangerous over-heating of the core.

9) The circulation scheme of LBC provides elimination of water/steam ingress into the core in an event of SG leak due to effective gravitational separation of steam on a free LBC level in the monoblock.

\subsection{Reasoning the Option for Reactor Power Level}

The option for the reactor power level to be 100 MWe or $280 \mathrm{MW}$ and, consequently, the option for the reactor dimensions has been reasoned by the following:

1) The circulation scheme of LBC provides elimination of water/steam ingress into the core in an event of SG 
leak due to effective gravitational separation of steam on a free LBC level in the monoblock.

2) On the other hand, this is the maximal power at which the dimensions of the reactor monoblock assure an opportunity of its transportation in complete factory readiness by railway. Therefore, the opportunities of choosing the sites for NPP construction will be considerably extended, the labor inputs and the schedule of NPP construction will be essentially reduced.

3) The selected power level assures the favorable conditions for passive removal of residual heat decay via the reactor monoblock vessel without dangerous increase of fuel elements' temperature and these principally simplify the design and safety systems of the RF.

4) The solution to the problem of seismic resistance of the RF is simplified due to comparatively low weight of the monoblock.

In accordance with computations, the selected power level assures the following [13]:

- Lifetime duration is $\sim 50,000$ full power hours provided the mastered oxide uranium fuel is used (CBR = $0.84)$.

- $\mathrm{CBR} \geq 1$ provided the MOX fuel is used, and the reactor operates in the closed fuel cycle in a mode of fuel self-providing when lifetime duration is 76,000 full power hours.

- Lifetime duration is $\sim 76,000$ full power hours provided uranium nitride fuel is used (CBR $=0.91$ ) and burn-up reactivity margin is less than $1 \$$ or lifetime duration is $\sim 150,000$ full power hours.

- $\mathrm{CBR} \geq 1$ provided the mixed nitride fuel is used, and the reactor operates in a mode of fuel self-providing at burn-up reactivity margin being less than $1 \$$ and lifetime duration is 76000 full power hours or the reactor operates in a mode of extended breeding with $\mathrm{CBR}=1.13$ at a doubling time of plutonium being $\sim 45$ years and lifetime duration being 200,000 full power hours.

For the experimental-industrial power-unit with RF SVBR-100 the lifetime duration of 50000 full power hours has been validated for oxide uranium fuel. For other kinds of fuel the extended lifetime needs experimental verification.

The basic parameters of RF SVBR-100 are summarized in Table 1 (reference variant).

\subsection{Decreasing the NFM Proliferation Risk}

The solution to the problem of non-proliferation can be only achieved by coupling both technological and political measures. The relationship of those measures will be different for nuclear and non-nuclear countries. During the recent decades all nuclear countries, which are the members of the "Nuclear Club" community and legally

\section{Table 1. Basic parameters of RF SVBR-100.}

\begin{tabular}{|c|c|}
\hline Parameter & Value \\
\hline RF thermal power, MW & 280 \\
\hline RF electric power, MWe & 100 \\
\hline Steam-producing rate, $\mathrm{t} / \mathrm{h}$ & 580 \\
\hline Produced steam parameters: pressure, $\mathrm{MPa} /$ temperature, ${ }^{\circ} \mathrm{C}$ & $6.7 / 278$ \\
\hline LBC temperature: inlet/outlet, ${ }^{\circ} \mathrm{C}$ & $340 / 490$ \\
\hline Average power density of the core, $\mathrm{kW} / \mathrm{dm}^{3}$ & 160 \\
\hline Average linear load of the fuel element, $\mathrm{kW} / \mathrm{m}$ & 26 \\
\hline $\begin{array}{c}\text { Fuel: type } \\
\text { U loading, kg } \\
\text { average enrichment in U-235, \% }\end{array}$ & $\begin{array}{l}\mathrm{UO}_{2} \\
\sim 9200 \\
\sim 16.7\end{array}$ \\
\hline Core lifetime, thousands of full power hours & 50000 \\
\hline Time interval between refueling, years & $\sim 7-8$ \\
\hline RMB dimensions: diameter $\times$ height, $\mathrm{m}$ & $4.53 \times 7.55$ \\
\hline RMB weight without core and coolant, $\mathrm{t}$ & 360 \\
\hline
\end{tabular}


possess the nuclear weapons, have solved this problem successfully, by use of the measures of physical protection, accounting, and safeguard. For that reason, the additional measures on technological maintenance of nonproliferation will be justified if they do not reduce the NPT competitiveness.

When NPPs are used in developing countries, the additional measures on technological maintenance of non-proliferation should be implemented, together with political measures and international control [14].

The duration of fuel lifetime makes possible perform refueling not often than once a 7 - 8 year period. At this point, the heavy refueling equipment is not delivered to the User-Country and refueling is performed by the Supplier-Country under the IAEA aegis. Fresh fuel is delivered to the NPP site directly before loading in the reactor. The unloaded SNF will be stored in the protected storage at the NPP site five years or less in order to reduce residual heat release to the values, which assure its safe transportation in special containers to the Supplier-Country. All transport and technological operations must be performed under the aegis of IAEA.

When uranium fuel is used, uranium enriched in less than $20 \%$ will be used. At the stage of closing fuel cycle and SNF reprocessing, 2\% of fission products built-up in the SNF and all minor actinides (MA) will remain in the re-fabricated fuel, with an exception of curium that is separated and stored up to decay in plutonium with its returning back to the fuel cycle. Handling that fuel needs the special technological equipment. Use of that fuel makes easier account of fuel movements. Breeding zones, in which plutonium for weapons can be built-up, are also absent in the reactor.

When NPPs are used in developing countries, delivery of fresh fuel and return of SNF for storage and reprocessing in the Supplier-Country must be realized on a nondiscrimination basis by International Nuclear Fuel Cycle Centers in accordance with initiatives of Russia and USA Presidents.

\subsection{Modular Structure of Power-Unit NSSS}

Due to a modular structure of the NSSS of the power-unit it is possible [15]:

1) To provide higher reliability (tolerance to failures of the power-unit being a system composed of separate $\mathrm{RFs}$ ) and safety (to reduce the potential radiation risk) as compared with a power-unit based on a large capacity single reactor.

2) Not to organize a large capacity reserve PS in the areas of decentralized power supply.

3) To provide the loading factor (LF) to be not less than $90 \%$ due to long reactor operation without refueling. The LF will be only determined by reliability factors of the turbine installation. When each RF is shut down for refueling or maintenance, the power-unit's capacity will be reduced much less as compared with that of the power-unit based on a single reactor of large unit capacity.

4) To provide organization of large-scale (conveyer) production of reactor monoblocks (tens of monoblocks annually) and continuous work load of engineering factories. Thus, the manufacturing costs will be considerably reduced. As fabrication of the reactor monoblock of the RF does not require the unique engineering equipment as it is for high pressure vessels of thermal reactors, there is an opportunity to form a competitive market of producers.

5) To use the standard designs for different capacity power-units and factory production-line methods for their assembly and construction. Along with high quantity production of RFs, these assure reduction in the schedule and cost of power-units construction.

6) To locate the modular small and medium-sized NPPs in the centers of power consumption. Therefore, the expenditures for construction of high-voltage lines will be eliminated.

7) To provide an opportunity of phase implementation of the power-unit in operation with gradual raising of power capacity as the assembly and starting-up and adjustment works for the scheduled module have been completed. Thus, the pay-back term of the capital investments can be reduced due to earlier output of production and earlier beginning of credit repayment as compared with a power-unit based on the reactor of large unit capacity.

These all heighten much the consumer benefits of RF SVBR-100.

The NSSS modular structure and shipment of factory-ready modules assure reduction of the investment cycle of NPP construction that is extremely viable for approaching the NPP technical and economic parameters to those of modern TPPs with short investment cycles. Therefore, the financial risks can be considerably reduced.

As there are only two states of RF functioning, namely, operating and shut down, control of the modular NSSS is carried out by one operator using the common power master unit. If there is any fault in a single RF, it 
is automatically shut down and is cooled down autonomously, away from the turbine installation systems.

On expiring the RF lifetime (50 - 60 years) and unloading the spent nuclear fuel and LBC, the basic RF element-reactor monoblock - will be decommissioned and placed in a storage of solid radioactive waste. A new reactor monoblock will be installed instead. The other elements of the RF and power-unit can be decommissioned and replaced as well, i.e. the renovation can be performed. At this point, the lifetime of the modular NPP will be only limited by that of reinforced-concrete construction structures and can be expanded up to $100-120$ years while the costs being much less as compared to those required for construction of the new power-unit. When the power-unit has been completely decommissioned, practically no radioactive materials will remain in the NSSS building after the reactor monoblocks have been dismantled. Thus, the cost of decommissioning will be considerably reduced.

\subsection{High Potential for Improvement}

The innovative Project of the NPP with reactor facilities SVBR-100 is in fact the First Generation Design based on a conservative approach. It has predetermined a high potential for further improvement of the Project that will be realized as the corresponding $\mathrm{R} \& \mathrm{D}$ have been accomplished and operating experience has been gained.

Especially:

- Increasing the LBC temperature at the reactor outlet while increasing the value of maximal temperature of the fuel element's cladding from $620^{\circ} \mathrm{C}$ to $650^{\circ} \mathrm{C}$ (there are all the necessary backgrounds) will provide (as the computations have revealed) growth of the reactor thermal power by $10 \%$ without considerable change of the reactor design.

- Use of the once-through SG generating super-heated steam assures that the efficiency of the thermodynamic cycle will be heightened by about $10 \%$, capital costs will be lowered, RF design will be simplified.

- Use of nitride fuel can provide twice increase of the reactor lifetime (the operability of fuel elements should be verified) and correspondingly reduce the consumption of fuel.

\subsection{Commercialization Concept}

Despite the maximal possible use of experience of operating the LBC cooled reactors at the NSs, the conditions of operating the equipment of NS RFs and NPP RFs are much different. The operating mode of NS RFs is characterized by operation mainly at low power levels under lowered LBC temperatures, whereas the NPP RFs operate mainly at nominal power. Moreover, the requirements to the lifetime of the NPP RFs equipment are much higher than those to the lifetime of the NS RFs equipment. The technical and economical parameters also need direct verification. These all require construction of the experimental-industrial power-unit with RF SVBR-100.

The RF inherent self-protection and passive safety properties can be demonstrated in controlled conditions at the experimental-industrial RF equipped with additional sensors and devices, while simulating all possible combinations of the equipment failures, personnel's errors and malevolent actions.

After performing the certified tests of the experimental-industrial power-unit and verifying the design characteristics the SVBR-100 RF will be ready for commercialization and wide use as a part of the NPP power-units of different capacity and purpose.

\section{Conclusions}

- The most expedient way to upgrade the NPP safety and at the same time improve the economic characteristics is use of RFs, in which the value of stored potential energy is the lowest and inherent self-protection and passive safety properties can be realized to the maximal extent.

- Those RFs cannot amplify the external impacts, therefore, the scale of damages will be only determined by the energy of the external impact, the exhaust of radioactivity being localized. Such type RFs will possess the robustness properties ensuring their enhanced stability not only in events of single failures of the equipment and personnel's errors, but also in events of malevolent actions. And that is especially important for development of nuclear power in the developing countries with a high threat of terrorism.

- The innovative nuclear power technology based on multi-purposed standardizated modular fast reactors with HLMC, i.e. SVBR-100, which possess developed inherent self-protection and passive safety properties, assures a high level of social acceptability for those reactors and provide the conditions for their use in devel- 
oping countries. Due to low amount of potential energy stored in coolant, specific design of the RF, the opportunity for severe accident such as those at NPPs TMI-2, Chernobyl, Fukushima 1 are deterministically eliminated (on the assumption the initial events are identical).

- The modular structure of the power-unit's NSSS provides an opportunity to changeover to the advanced technologies of the standard design for different capacity power-units on the basis of series factory-manufacture of standardizated reactor modules and changeover to production-line methods for their assemblage. This will make possible considerably reduce the schedule period required for NPP construction as well as provide technical maintenance of the reactor modules on a servicing base. Thus, the number of the operating personnel and corresponding expenditures will be reduced.

- The conservative approach adopted in the RF design has predetermined a high potential to further improvement of the RF. Realization of the designated measures that requires performing the corresponding R \& D will make it possible to bring closer the specific capital cost of constructing the modular NPP and the construction schedule to the values, which are typical for modern TPPs. This will heighten the NPP competitiveness at the investment market and provide the conditions for attraction of non-governmental investments.

- The considered NPT possesses the properties making possible realization of the concept: "build, own, operate (or lease), deliver fresh fuel, take back the spent fuel, take the risks associated with potential nuclear detriment during the lifetime" that is most attractive for developing countries and though that concept is more burdensome for the Supplier-Country. Of course, if the User-Country wants to develop the own nuclear technology and not only use its products, the different concepts of the life cycle with extended participation of the User-Country are possible.

- Specific features of the proposed NPT make expedient its use in developing countries as a source of electric and heat energy that is located at a short distance from the consumer and for water desalination

- Development of experimental-industrial power-unit with the SVBR-100 type reactor facility is provided in Federal Target Program "New Generation Nuclear Power Technologies for 2010-2015 Years and Future Trends up to 2020". There will be only one-time expenditures for demonstration of the present NPT as on the basis of the tested "standard" reactor module the nuclear power-units of different capacities and purposes can be constructed without performing the additional R\&D. The project will be realized within the frameworks of a state-private partnership, for which a joint venture consisting of State Atomic Energy Corporation "Rosatom" and private company JSC "Irkutskenergo" is organized, its name is JSC “AKME-engineering”. It is expected that the presented NPT will be ready for commercialization in the developing countries in 20222025.

\section{Acknowledgements}

The authors would like to thank SSC RF-IPPE employees S.V. Budarina, K.G. Melnikov, I.V. Tormyshev for the assistance in preparation of the present Paper.

\section{References}

[1] Spievak, I. and Weinberg, A.M. (1985) Inherently Safe Reactors. Annual Review of Energy, 10, 431-462. http://dx.doi.org/10.1146/annurev.eg.10.110185.002243

[2] Forsberg, C.W. and Weinberg, A.M. (1990) Advanced Reactors, Passive Safety, and Acceptance of Nuclear Energy. Annual Review of Energy, 15, 133-152. http://dx.doi.org/10.1146/annurev.eg.15.110190.001025

[3] Arutyunyan, R.V. (2013) Have We Got Safety Culture? Atomnaya Strategiya, 83, 9-11. http://www.proatom.ru/

[4] Nuclear Terrorism. http://www.gochs.info/p669.htm

[5] IAEA (2006) Advanced Nuclear Plant Design Options to Cope with External Events. IAEA-TECDOC-1487. http://www-pub.iaea.org/MTCD/publications/PDF/te_1487_web.pdf

[6] Ammirabile, L. European Project SARGEN_IV: Safety Approach and Assessment of GEN IV Reactors. http://www.iaea.org/NuclearPower/Downloadable/Meetings/2013/2013-02-26-02-27-TM-SFR/day-1/4-L.AmmirabileEC.pdf

[7] Toshinsky, G.I., Komlev, O.G., Tormyshev, I.V. and Petrochenko, V.V. (2013) Effect of Potential Energy Stored in Reactor Facility Coolant on NPP Safety and Economic Parameters. World Journal of Nuclear Science and Technology, 3, 59-64. http://www.scirp.org/journal/wjnst

[8] Toshinsky, G.I., Komlev, O.G., Stepanov, V.S., et al. (2007) Principles of Providing Inherent Self-Protection and Pas- 
sive Safety Characteristics of the SVBR-75/100 Type Modular Reactor Installation for Nuclear Power Plants of Different Capacity and Purpose. Paper No. 175598. International Conference Advanced Nuclear Fuel Cycles and Systems (GLOBAL'07), Boise, 9-13 September 2007.

[9] Bolhovitinov, V.D., Pankratov, D.V., Toshinsky, G.I., et al. (2003) Assessment of Radiation Consequences Caused by Large Tightness Failure in the Primary Circuit Gas System of RF SVBR-75/100 with Simultaneous Coolant Heating up to $600^{\circ}$ C. Paper No. 2203 (CD-ROM), 3rd Conference Heavy-Liquid Metal Coolants in Nuclear Technologies (HLMC-2003) within the Frameworks of Russian Scientific and Technical Forum Nuclear Fast Neutron Reactors, Obninsk, 4-12 December 2003.

[10] IAEA (2012) Safety of Nuclar Power Plants: Design, Specific Safety Requirements. IAEA Safety Standards Series No. SSR-2/1.

[11] Zrodnikov, A.V., Toshinsky, G.I., Stepanov, V.S., et al. (2008) Innovative Nuclear Technology Based on Modular Multi-Purpose Lead-Bismuth Cooled Fast Reactors. Progress in Nuclear Energy, 50, 170-178. http://dx.doi.org/10.1016/j.pnucene.2007.10.025

[12] Zrodnikov, A.V., Toshinsky, G.I., Stepanov, V.S., et al. (2004) Lead-Bismuth Reactor Technology Conversion: From Nuclear Submarine Reactors to Power Reactors and Ways to Increase the Investment Attractiveness of Nuclear Power Based on Fast-Neutron Reactors. Proceedings of IAEA International Conference "Fifty Years of Nuclear Power-The Next Fifty Years”, Report IAEA-CN-A3, Obninsk.

[13] Novikova, N.N., Komlev, O.G. and Toshinsky, G.I. (2006) Neutronic and Physical Characteristics of Reactor SVBR75/100 with Different Types of Fuel. Proceedings of International Congress on Advances in Nuclear Power Plants, CD-ROM, Paper No. 6355, Reno, 4-8 June 2006.

[14] Gromov, B.F., Toshinsky, G.I., Zrodnikov, A.V., Dragunov, Yu.G., Stepanov, V.S., et al. (2001) Nuclear Power Complex Based on SVBR-75/100 Small Reactors Cooled by Lead-Bismuth Liquid Metal Coolant. Competitiveness, Simplified Life Cycle, Safety, Non-Proliferation. Proceedings of IAEA International Seminar on Status and Prospects for Small and Medium Sized Reactors, Cairo, 27-31 May 2001.

[15] Zrodnikov, A.V., Toshinsky, G.I., Komlev, O.G., et al. (2006) Nuclear Power Development in Market Conditions with Use of Multi-Purpose Modular Fast Reactors SVBR-75/100. Nuclear Engineering and Design, 236, 1490-1502. http://dx.doi.org/10.1016/j.nucengdes.2006.04.005 